\title{
Effects of COVID-19 Pandemic on Lifestyle Behaviours among Italian Physically Active Population
}

\author{
Myriam Galfo $^{1}$, Fabrizia Maccati ${ }^{1}$, Francesca Melini ${ }^{1}$ \\ ${ }^{1}$ Council for Agricultural Research and Economics - Research Center on Food and Nutrition (CREA), Via \\ Ardeatina 546, Rome, I-00178 Italy.
}

Corresponding Author: Myriam Galfo

\begin{abstract}
Objective: The 2019 coronavirus disease (COVID-19) is a global public health emergency resulting in lockdowns, associated food habits and lifestyle changes and constraint public health delivery. The aim of this study was to investigate the impact of the COVID-19 induced lockdown in Italy on lifestyle behaviours among physically active population adults.

Materials and Methods: A cross-sectional online survey was conducted from April to June 2020 on 175 subjects (48.6\% males and 18-66 age range) by a structured questionnaire to collect information on demographic characteristics, anthropometric data, lifestyle factors and dietary habits.

Results: It merged that $40 \%$ of the sample gained weight $(\approx 1 \mathrm{~kg})$ with no significant differences between genders. Alcohol consumption and physical activity practice and duration significantly decreased during lockdown, while physical activity frequency, sedentary activities, sleep times, daily breakfast habits and consumption of sweets significantly increased. A multiple logistic regression model showed that education level, nutritional status, frequency of physical activity, eating between meals, and sweet consumption had a significant effect on weight gain during COVID-19.

Conclusions: Lockdown had a bi-directional impact (both positive and negative) on lifestyle changes, because more time was spent at home. These results need to be confirmed with further longitudinal studies among a larger population sample to better understand the lasting effects of this pandemic on lifestyle behaviors and their changes.
\end{abstract}

Keywords: Covid-19, lifestyle behaviour, lockdown, pandemic, physical activity.

\section{INTRODUCTION}

The World Health Organization (WHO) announced on March 11, 2020 the outbreak of the novel 2019 coronavirus disease (COVID-19) and declared it a global pandemic. ${ }^{1}$ The COVID-19 has had farreaching health, social, and economic implications related also to the measures taken by Governments. ${ }^{2}$

At its outbreak, the Italian Government decided stringent containment measures to contrast and contain the spread of COVID-19 pandemic, such as the ban on mass gatherings and events, and on meeting up for no urgent reasons. The \#iorestoacasa
Italian decree (translated as \#stayathome decree) involved a sudden and drastic change in the habits and lifestyles of the population, as well as a severe reduction of socialization. Physical distancing and selfisolation strongly impacted citizens' lives, and mainly affected daily eating habits and behaviours. $^{3}$

In fact, the COVID-19 control measures and travel restrictions have compromised the ability to keep physical activity and maintain healthy lifestyles, and often determined reduced consumption of healthy diets. 
Practice of physical activity (PA) was initially allowed for both athletes and amateurs provided that the interpersonal distance of at least one meter was maintained. Then, all activities practiced in gyms, sport centers and swimming pools were interrupted, and closure was laid down. At a later stage, access to public parks and gardens was also prohibited to further counteract the spread of the virus. In addition, the practice of outdoor recreational PA was allowed only near homes, not in group-based settings, and provided that the distance of at least one meter from other people was respected. Because of these increasingly restrictive containment measures, practice of PA has been progressively limited. ${ }^{4}$

Considering that adults are recommended to have at least $150 \mathrm{~min}$ of moderate physical activity per week to prevent weight gain, ${ }^{5}$ it is pivotal to remain physically active by frequent walking, jogging, cycling, doing physical exercises recreationally or utilitarian.

The aim of this study was to investigate the effects of the COVID-19, induced by the lockdown in Italy, on lifestyle behaviours among physically active adult population.

\section{MATERIALS AND METHODS Study design and data collection}

The survey was conducted from April to June 2020, among the Italian physically active population, by means of an online platform, accessible through any device with Internet connection. The survey was available through private social networks (e.g., WhatsApp, Twitter, Facebook). A total of 175 participants completed the questionnaire. The survey was carried out in agreement with the Declaration of Helsinki (2000) and national and international regulations. All participants were informed about the study and on the fact that data were analyzed for research purposes only and for possible publication, in accordance with current privacy regulations, and agreed to participate in the data collection. Participants' personal information was anonymous to maintain and protect confidentiality. Given the anonymous nature of the survey carried out via web, which does not allow tracking of sensitive personal data, this study did not require the approval of the ethics committee. The final database was downloaded as a Microsoft Excel sheet.

\section{Questionnaire}

The questionnaire was built ad hoc by using Google Form and included a total of 51 questions organized into 4 sections: (1) personal data (i.e., questions on age, gender, hometown, current employment and especially possibility of working at home); (2) anthropometrics information (i.e., questions on reported weight and height, and if weight had increased during lockdown); (3) lifestyle factors (i.e., questions about smoke and alcohol habits, hours of sleep, PA in terms of activity type, frequency and duration of practice, time spent in studying, watching TV, and other pastimes, such as reading, cooking, using social networks before and during the lockdown); (4) dietary habits information (i.e., questions on breakfast habits, daily consumption of certain foods, such as as sweet and fruit and vegetables, and eating between meals).

\section{Anthropometric data}

Height and weight information retrieved by the questionnaire was all selfreported by the respondents. Body Mass Index (BMI) was calculated as the weight in kilograms divided by the square of the height in meters $\left(\mathrm{kg} / \mathrm{m}^{2}\right)$. Weight status was classified according to $\mathrm{WHO}^{6}$ categories as follows: underweight (BMI < 18.5), normal weight (BMI between 18.5-24.9), overweight (BMI between 25 and 29.9) and obese $(\mathrm{BMI} \geq 30)$.

\section{Statistical analysis}

The descriptive analyses were presented as means \pm standard deviations for quantitative variables, and as 
percentages for categorical variables. Chisquare test and T-tests were used to test for significant proportion and mean differences, respectively, while McNemar analysis was used to investigate the difference between categorical variables before and during the COVID-19 emergency.

A multiple logistic regression model, backward stepwise method, was employed to evaluate the association of selected lifestyle factors and weight gain (dependent variable). Analyses were conducted with unadjusted and adjusted covariates.

For all the tests, p-values $<0.05$ were considered to be statistically significant. All statistical analyses were performed using MedCalc Software version 19.4.0 for Windows.

\section{RESULTS}

Characteristics of the study participants are shown in Table 1. The percentage of females in the sample slightly exceeded that of males $(51.4 \%$ vs $48.6 \%$, respectively). Subjects were $38.1 \pm 14.5$ years of age and had weight $71.2 \pm 13.5 \mathrm{~kg}$, height $172.7 \pm 10.3 \mathrm{~cm}$, BMI $23.7 \pm 3.0$ $\mathrm{kg} / \mathrm{m}^{2}$. During COVID-19, weight was 72.1 $\pm 13.8 \mathrm{~kg}$ and BMI $24.1 \pm 3.2 \mathrm{~kg} / \mathrm{m}^{2}$, as a matter of fact $40 \%$ of the sample gained weight without significant differences between genders. The prevalence of overweight/obesity was $32.6 \%$ with higher and significant values in males than females (44.7\% vs 21.1\%; $\mathrm{p}=0.0009$ ). Also, the percentage of the sample who attended high school was higher than those who had university degree and who had less than middle school (respectively $55.4 \%$ vs $34.3 \%$ and $10.3 \%$ ) with no significant differences between females and males.

\begin{tabular}{|c|c|c|c|c|}
\hline Characteristics & $\begin{array}{l}\text { All sample } \\
\mathrm{n}=175(100 \%)\end{array}$ & $\begin{array}{l}\text { Males } \\
n=85(48.6 \%)\end{array}$ & $\begin{array}{l}\text { Females } \\
\mathrm{n}=90(51.4 \%)\end{array}$ & p-value \\
\hline Age (years) & $38.1 \pm 14.5$ & $39.0 \pm 14.8$ & $37.2 \pm 14.4$ & $<0.0001^{\mathrm{a}}$ \\
\hline Weight $(\mathrm{kg})$ & $71.2 \pm 13.5$ & $80.3 \pm 11.1$ & $62.6 \pm 9.3$ & $<0.0001^{\mathrm{a}}$ \\
\hline Height $(\mathrm{cm})$ & $172.7 \pm 10.3$ & $180.5 \pm 7.1$ & $165.3 \pm 6.7$ & $<0.0001^{\mathrm{a}}$ \\
\hline BMI & $23.7 \pm 3.0$ & $24.6 \pm 2.7$ & $22.9 \pm 3.1$ & $<0.0001^{\mathrm{a}}$ \\
\hline Weight during COVID-19 & $72.1 \pm 13.8$ & $81.3 \pm 11.5$ & $63.5 \pm 9.7$ & $<0.0001^{\mathrm{a}}$ \\
\hline BMI during COVID-19 & $24.1 \pm 3.2$ & $24.9 \pm 2.8$ & $23.2 \pm 3.4$ & $<0.0001^{\mathrm{a}}$ \\
\hline \multicolumn{5}{|l|}{ Age class } \\
\hline $18-30$ & $67(38.3)$ & $30(35.3)$ & $37(41.1)$ & $0.1646^{\mathrm{b}}$ \\
\hline $31-50$ & $52(29.7)$ & $22(25.9)$ & $30(33.3)$ & \\
\hline $51-66$ & $56(32.0)$ & $33(38.8)$ & $23(25.6)$ & \\
\hline \multicolumn{5}{|l|}{ Education } \\
\hline Less than middle school & $18(10.3)$ & $10(11.8)$ & $8(8.9)$ & $0.7464^{b}$ \\
\hline High School & $97(55.4)$ & $45(52.9)$ & $52(57.8)$ & \\
\hline \multirow{2}{*}{$\begin{array}{l}\text { University degree } \\
\text { Nutritional status }\end{array}$} & $60(34.3)$ & $30(35.3)$ & $30(33.3)$ & \\
\hline & & & & \\
\hline \begin{tabular}{l|l} 
& Normal weight
\end{tabular} & $118(67.4)$ & $47(55.3)$ & $71(78.9)$ & $0.0009^{\mathrm{b}}$ \\
\hline \multirow{2}{*}{$\begin{array}{l}\text { Overweight/obese } \\
\text { Smartworking }\end{array}$} & $57(23.6)$ & $38(44.7)$ & $19(21.1)$ & \\
\hline & & & & \\
\hline \begin{tabular}{l|l} 
& Yes
\end{tabular} & $65(37.1)$ & $33(38.8)$ & $32(35.6)$ & $0.6557^{\mathrm{b}}$ \\
\hline \multirow{2}{*}{\begin{tabular}{l|l} 
& No \\
\end{tabular}} & $110(62.9)$ & $52(61.2)$ & $58(64.4)$ & \\
\hline & \multicolumn{4}{|c|}{ Weight changes during COVID-19 } \\
\hline Gained & $70(40)$ & $35(41.2)$ & $35(38.9)$ & $0.7582^{\mathrm{b}}$ \\
\hline No changes & $105(60)$ & $50(58.8)$ & $55(61.1)$ & \\
\hline
\end{tabular}

Table 2 shows the changes in lifestyle-related practice before and during COVID-19. Alcohol consumption and the practice and duration of PA significantly decreased during lockdown (from $78.9 \%$ to $62.3 \%$; $\mathrm{p}<0.0001$ for alcohol, from $100 \%$ to $85.7 \%$; $<<0.0001$ for practice of $\mathrm{PA}$, and from $71.5 \%$ to $44.3 \%$; $p<0.0001$ for 60 or more minutes a day of PA), even if the daily frequency of PA increased significantly (from $6.4 \%$ to $16.0 \%$; $=0.0041$ for everyday PA). Also smoking decreased during the covid-19 pandemic but not significantly. 
Table 2. Behaviour lifestyle pre and during COVID-19

\begin{tabular}{|c|c|c|c|}
\hline Variables & Pre COVID-19 & During COVID-19 & $p$-value \\
\hline \multicolumn{4}{|l|}{ Smoking } \\
\hline Yes & $34(19.4)$ & 29 (16.6) & 0.0625 \\
\hline No & $141(80.6)$ & $146(83.4)$ & \\
\hline \multicolumn{4}{|c|}{ Alchol consumption } \\
\hline Yes & $138(78.9)$ & $109(62.3)$ & $<0.0001^{*}$ \\
\hline No & $37(21.1)$ & $66(37.7)$ & \\
\hline \multicolumn{4}{|l|}{ Sleep time } \\
\hline$\geq 7 \mathrm{~h}$ & $109(62.3)$ & $127(72.6)$ & $0.0175^{*}$ \\
\hline$<7 \mathrm{~h}$ & $66(37.7)$ & $48(27.4)$ & \\
\hline \multicolumn{4}{|l|}{ Physical activity } \\
\hline Yes & $175(100)$ & $150(85.7)$ & $<0.0001^{*}$ \\
\hline No & $0(0.0)$ & $25(14.3)$ & \\
\hline$\geq 60 \mathrm{~min}$ & $113(71.5)$ & $70(44.3)$ & $<0.0001^{*}$ \\
\hline$<60 \mathrm{~min}$ & $45(28.5)$ & $88(55.7)$ & \\
\hline Every day & $10(6.4)$ & $25(16.0)$ & $0.0041^{*}$ \\
\hline No every day & $146(93.6)$ & $131(84.0)$ & \\
\hline \multicolumn{4}{|l|}{ Watching Tv } \\
\hline $\begin{array}{l}\geq 2 \mathrm{~h} / \text { day } \\
<2 \mathrm{~h} / \text { day }\end{array}$ & $\begin{array}{l}68(38.9) \\
107(61.1)\end{array}$ & $\begin{array}{l}99(56.6) \\
76(43.4)\end{array}$ & $<0.0001^{*}$ \\
\hline \multicolumn{4}{|l|}{ Study time } \\
\hline $\begin{array}{l}\geq 2 \mathrm{~h} / \text { day } \\
<2 \mathrm{~h} / \text { day }\end{array}$ & $\begin{array}{l}71(40.6) \\
104(59.4)\end{array}$ & $\begin{array}{l}81(46.3) \\
94(53.7)\end{array}$ & $0.0414^{*}$ \\
\hline \multicolumn{4}{|l|}{ Other pasttimes } \\
\hline $\begin{array}{l}\geq 2 \mathrm{~h} / \text { day } \\
<2 \mathrm{~h} / \text { day }\end{array}$ & $\begin{array}{l}85(48.6) \\
90(51.4)\end{array}$ & $\begin{array}{l}125(71.4) \\
50(28.6)\end{array}$ & $<0.0001^{*}$ \\
\hline $\begin{array}{l}\text { Breakfast habits } \\
\text { Every day } \\
\text { No every day }\end{array}$ & $\begin{array}{l}138(78.9) \\
37(21.1) \\
\end{array}$ & $\begin{array}{l}151(86.3) \\
24(13.7) \\
\end{array}$ & $0.0044^{*}$ \\
\hline \multicolumn{4}{|c|}{ Eating between meals } \\
\hline Yes & $103(58.9)$ & $113(64.6)$ & 0.1539 \\
\hline No & $72(41.1)$ & $62(35.4)$ & \\
\hline \multicolumn{4}{|c|}{ Fruit and vegetable consumption } \\
\hline$\geq 5$ serving/day & $3(1.7)$ & $7(4.0)$ & 0.1250 \\
\hline$<5$ serving/day & $172(98.3)$ & $168(96.0)$ & \\
\hline \multicolumn{4}{|c|}{ Sweet consumption } \\
\hline$\geq 1$ serving/day & $49(28.0)$ & $61(34.9)$ & $0.0169^{*}$ \\
\hline$<1$ serving/day & $126(72.0)$ & $114(65.1)$ & \\
\hline
\end{tabular}

p-value according to McNemar test; *statistical significance is expressed as $p<0.05$ exp

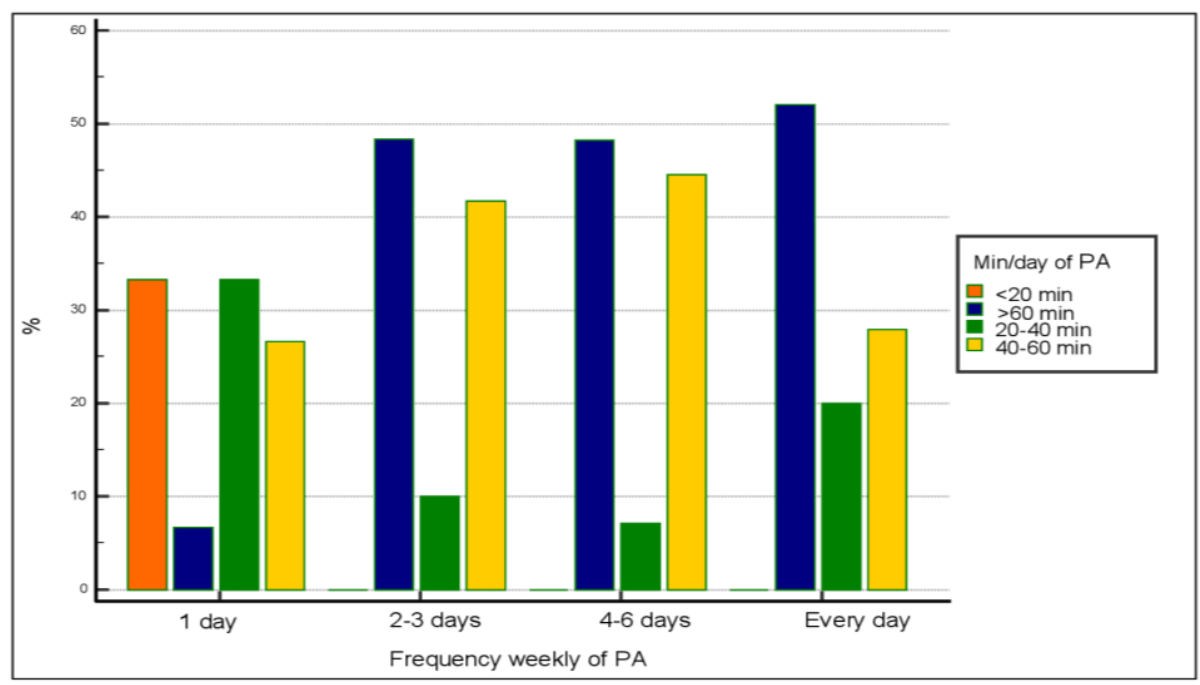

Figure 1 Physical activity (PA) during lockdown

Sedentary activities (e.g., watching TV, study time and other pastimes, such as reading, cooking, using social networks), sleep time, daily breakfast habit, and consumption of sweet significantly increased during lockdown. In particular, watching TV for 2 or more hours a day increased from $38.9 \%$ to $56.6 \%$ (p $<0.0001)$; studying for 2 or more hours a day raised from $40.6 \%$ to $46.3 \%$ 
$(\mathrm{p}=0.0414)$; the percentage of those who spend 2 or more hours in other pastimes increased from $48.6 \%$ to $71.4 \%$ ( $\mathrm{p}<0.0001$ ). Also the percentage of those who sleep 7 or more hours a night (as per international recommendations) increased from $62.3 \%$ to $72.6 \%(p=0.0175)$, while the habit of having breakfast every day and the consumption of 1 or more serving a day of sweets increased from $78.9 \%$ to $86.3 \%$ (p0.0044) and from $28.0 \%$ to $34.9 \%$ ( $\mathrm{p}=$ 0.0169 ), respectively. In addition fruit and vegetable consumption and eating between meals increased, but not significantly.

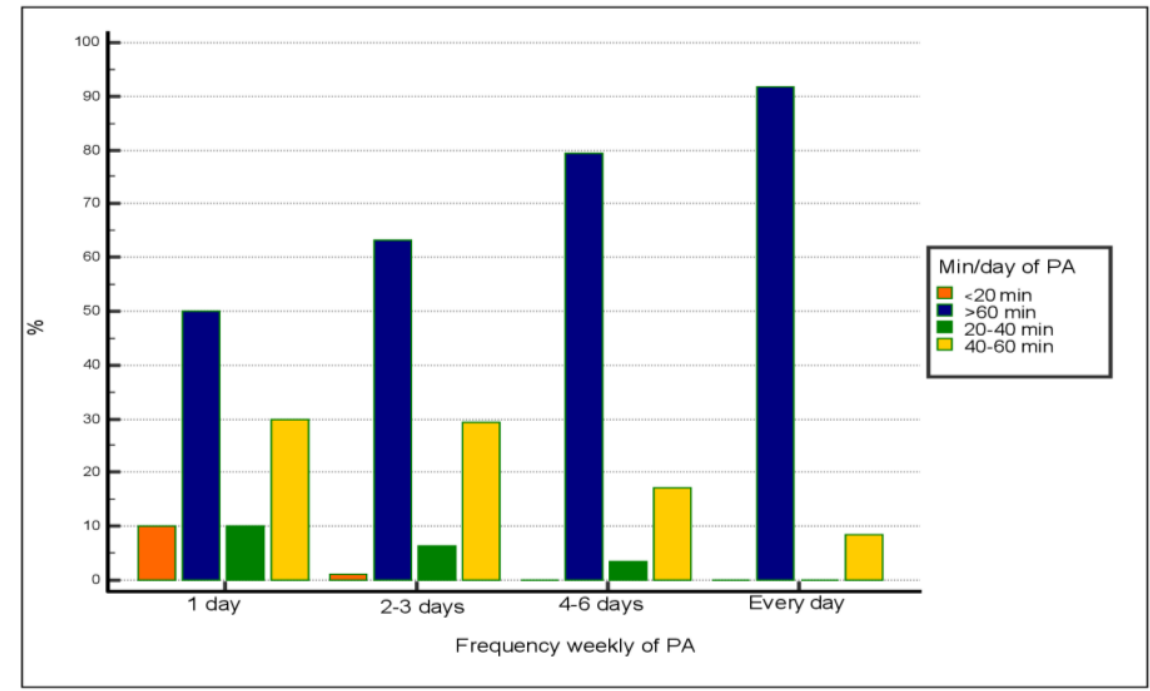

Figure 2 Physical activity (PA) before lockdown

Table 3. Association between selected lifestyle factors and weight gain. Odds ratios (OR) and $95 \%$ Confidence Intervals (CI) from logistic regression analysis

\begin{tabular}{|c|c|c|c|c|}
\hline \multirow[t]{2}{*}{ Independent variables } & \multicolumn{2}{|l|}{ Weight gain } & \multirow[b]{2}{*}{ aOR $(95 \%$ CI) } & \multirow[b]{2}{*}{$p$-value } \\
\hline & $\operatorname{cOR}(95 \% \mathrm{CI})$ & $p$-value & & \\
\hline \multicolumn{5}{|l|}{ Gender } \\
\hline Males vs females & $1.100(0.601-2.015)$ & 0.7575 & $0.997(0.459-2.167)$ & 0.9941 \\
\hline \multicolumn{5}{|l|}{ Age } \\
\hline $31-66$ vs $18-30$ & $1.200(0.642-2.243)$ & 0.5679 & $2.557(0.972-6.725)$ & 0.0571 \\
\hline \multicolumn{5}{|l|}{ Education level } \\
\hline High school and less vs University & $1.720(0.892-3.316)$ & 0.1057 & $2.955(1.170-7.468)$ & $0.0220 *$ \\
\hline \multicolumn{5}{|l|}{ Nutritional status } \\
\hline Overweight/obese vs normal weight & $2.695(1.406-5.163)$ & $0.0028^{*}$ & $3.120(1.309-7.436)$ & $0.0103 *$ \\
\hline \multicolumn{5}{|l|}{ Physical activity } \\
\hline No vs yes & $1.000(0.421-2.373)$ & 1.0000 & $0.218(0.018-2.592)$ & 0.2276 \\
\hline \multicolumn{5}{|l|}{ Frequency physical activity } \\
\hline No every day vs every day & $4.044(1.315-12.440)$ & $0.0148^{*}$ & $6.053(1.689-21.691)$ & $0.0057^{*}$ \\
\hline \multicolumn{5}{|l|}{ Breakfast habit } \\
\hline No vs yes & $2.375(0.989-5.704)$ & 0.0530 & $1.984(0.598-6.575)$ & 0.2626 \\
\hline \multicolumn{5}{|l|}{ Eating between meals } \\
\hline Yes vs no & $1.495(0.785-2.847)$ & 0.2213 & $2.593(1.069-6.287)$ & $0.0350 *$ \\
\hline \multicolumn{5}{|l|}{ Sweet consumption } \\
\hline$\geq 1$ serving/day vs $<$ serving/day & $1.987(1.054-3.745)$ & $0.0337 *$ & $2.966(1.292-6.809)$ & $0.0103 *$ \\
\hline \multicolumn{5}{|l|}{ Fruit and vegetable consumption } \\
\hline$<5$ serving/day vs $\geq 5$ serving $/ /$ day & $1.700(0.321-9.018)$ & 0.5331 & $1.486(0.162-13.677)$ & 0.7263 \\
\hline \multicolumn{5}{|l|}{ Watching TV } \\
\hline$>2$ hours/day vs $\leq 2$ hours/day & $1.263(0.684-2.332)$ & 0.4553 & $1.220(0.563-2.644)$ & 0.6147 \\
\hline \multirow{2}{*}{\multicolumn{5}{|c|}{ Sleep time }} \\
\hline$<7$ hours vs $\geq 7$ hours & & 0.3338 & $1.234(0.493-3.089)$ & 0.6535 \\
\hline
\end{tabular}

$c O R=$ Crude odds ratio; aOR $=$ Adjusted odds ratio; $C I=$ confidence interval, $p$-value according to Chi-square test $;$ *statistical significance is expressed as $p<0.05$

Regarding PA, the frequency and duration before and during the lockdown are shown in figures 1 and 2. It is interesting to highlight that before the pandemic, the increase in PA frequency also determined a greater duration of the activity, well beyond 
60 minutes; while during lockdown the subjects involved in the present study who stated that they continued being active, did PA every day but with less duration (40-60 min and 20-40 min).

Crude and adjusted odd ratios for lifestyle factors associated with weight pain, obtained from a multiple regression model are shown in Table 3. Education level, nutritional status, frequency of physical activity, eating between meals and sweet consumption had a significant effect on weight gain, whereas gender, age, physical activity, breakfast habits, fruit and vegetable consumption, watching TV and sleep time had no significant association. The results show that those who attended high school were at a three-fold higher risk of gaining weight compared to those who had university degree (aOR 2.96, 95\% CI 1.177.47, $\mathrm{p}=0.0220$ ). Also the obese/overweight were about 3 times more likely to be at risk of gaining weight than normal weight $(\mathrm{aOR}$ $3.12,95 \%$ CI 1.31-7.44, $\mathrm{p}=0.0103)$. In addition, those who were not physically active every day, were even 6 times at risk of gaining weight compared to those who did PA every day (aOR 6.05, 95\% CI 1.6921.69, $\mathrm{p}=0.0057$ ).

With regard to eating habits, those who ate between meals were 2.6 times at risk of gaining weight compared to those who did not eat snacks (aOR 2.59, 95\% CI 1.07-6.29, $\mathrm{p}=0.0350$ ), and those who consumed sweets one or more times a day were at a three-fold higher risk of gaining weight than to those who ate them less of once a day (aOR 2.97, 95\% CI 1.29-6.81, $\mathrm{p}=0.0103)$.

\section{DISCUSSION}

This cross-sectional study examined the effects of the COVID-19 pandemic induced by lockdown in Italy on lifestyle behaviours among physically active adult population.

Maintaining a healthy and balanced diet and being physically active are among the recommendations given at present to support the immune system. ${ }^{7}$ The current study showed that alcohol consumption smoking and the practice and duration of PA decreased during lockdown, while PA frequency, sedentary activities (e.g., watching TV, study time and other pastimes such as reading, cooking, using social networks), sleep time, breakfast habit every day, fruit and vegetable consumption, as well as eating between meals and consumption of sweets increased during lockdown.

The data on alcohol consumption is controversial. Some research reported an increase in alcohol consumption, ${ }^{8,9}$ while other studies reported a decrease. ${ }^{3,10}$

In this study a decline in physical activity of $15 \%$ and a reduction in time of activity were observed, with the sedentary activities (predominantly television viewing) being simultaneously prolonged; however, there was an increase of PA frequency every day. It is evident that the recommendations by the Government to limit movement outdoors and the restrictions on doing group sports, having walks, doing exercise and gym, accessing parks and sport grounds is related to the decrease in active participation in PA. However, thanks to PA classes at home through various social media platforms, as well as to other means such as treadmills or bodyweight training, present results show that it has been possible for individuals to maintain adequate and daily normal PA patterns with various home activities. A lot of studies reported a decrease of PA and increase in sitting or screen time during COVID-19 pandemic 10-15 while few researches observed opposite results showing an increase in PA. ${ }^{3,16}$ These differences may be related to the policies on movement restrictions taken by the different Governments during this period. ${ }^{17}$

Based on the results of the present study, more than $70 \%$ of participants met the recommended sleeping hours during the pandemic, compared to $60 \%$ before pandemic. Rienzo et al. reported that during lockdown people slept more hours than beforehand ${ }^{3}$ and similar surveys conducted 
in Spain showed that the number of short sleepers decreased during the first three weeks of lockdown. ${ }^{18}$ In the study of Cancello et al. $22 \%$ of subjects declared sleeping 1-2 hours more than usual, even if they described symptoms of insomnia and perceived sleep as less restful. ${ }^{19}$

The findings about changes in food habits went both towards positive and negative directions. If on the one hand there has been a strong increase in the consumption of sweets and eating between meals, on the other hand there has been, in fact, an improvement in the consumption of fruit and vegetables, as well as a significant increase of people who had breakfast daily. A possible explanation could be that, as people stayed at home during lockdown, there was more free time for cooking and eating either better or worse.

Similar results were reported by Scarmozzino and Visioli, who found that half of the participants of an Italian sample showed an increase in the consumption of sweets and about $21 \%$ increased the intake of fresh fruit and vegetables. ${ }^{20}$

In addition, our data confirm the previous findings that both positive and negative changes in food habits were observed during the pandemic: some studies showed more frequent and higher consumption of sweets, biscuits and cakes, a lower intake of fruit and vegetables, and more frequent eating out of control. . $^{8,9,11,13,15}$ Other surveys reported an increased consumption of fruit and vegetables and a decreased consumption of carbonated or sugary drinks. 3,10

The present study indicates that the COVID-19 pandemic and the subsequent lockdown resulted in self-reported weight gain of about $1 \mathrm{~kg}$ in less than half of the subjects. Lower education level, overweight/obese nutritional status, lack of daily PA, eating between meals, and greater sweet consumption were significantly associated with weight increase. Similar results were reported by a study from Dogas et al., where $30 \%$ of respondents affirmed, they had gained weight during the lockdown. ${ }^{21}$

Other studies also support our data on weight gain $3,9,13,17,22,23$ and evidence shows that even a small positive energy balance over time is enough to cause weight gain in many individuals. ${ }^{24}$

However, considering that about $60 \%$ of the respondents did not gain weight, the current study showed that this sample of sportsmen managed to keep fit during the lockdown.

Some limitations must be, however, acknowledged to the present study. Firstly, all data, including anthropometric measurement, PA, dietary habits, smoking and sleeping habits, were self-reported which may be less reliable and biased. In addition, BMI was calculated based on selfreported data on weight and height; it is thus possible that underestimation of overweight and obesity occured. Secondly, the crosssectional study that precludes the investigation of casual relationships was conducted on a small sample size.

Strength of our study was represented by the fact that it was the first survey conducted on a sample of physically active population in the most critical period of the COVID-19 epidemic in Italy.

\section{CONCLUSION}

This study provided information on lifestyle behaviours of a physically active sample during the COVID-19 pandemic in Italy. The lockdown had a bi-directional impact on lifestyle changes, both positive and negative, because more time was spent at home. In fact, if on the one hand alcohol consumption and smoking decreased, and time sleep, daily breakfast habit, fruit and vegetable consumption and daily frequency PA improved. On the other hand, sedentary activities, eating between meals, consumption of sweets increased, and practice and duration of PA worsen.

These results need to be confirmed with further longitudinal studies among a larger population sample to gain higher insight into the lasting effects of this 
pandemic on lifestyle behaviours and their changes.

\section{Acknowledgement}

The authors gratefully thank the people and their families who participated in this study.

\section{Funding Source}

This research did not receive any specific grant from funding agencies in the public, commercial, or not-for-profit sectors.

\section{Conflict of Interest}

The authors have no conflicts of interest to declare.

\section{Ethical Approval: Approved}

\section{REFERENCE}

1. Ghebreyesus TA. WHO Director-General's opening remarks at the media briefing on COVID-19-11 March 2020. World Health Organisation (WHO). Available at: https://www.who.int/dg/speeches/detail/who -director-general-s-opening-remarks-atthemedia-briefing-on-covid-19---11-march2020 (2020).

2. Pietrobelli A, Pecoraro L, Ferruzzi A, Heo M, Faith M, Zoller T, et al. Effects of COVID-19 Lockdown on Lifestyle Behaviors in Children with Obesity Living in Verona, Italy: A Longitudinal Study. Obesity 2020; 28:1382-5.

3. Di Renzo L, Gualtieri P, Pivari F, Soldati L, Attinà $\mathrm{A}$, Cinelli $\mathrm{G}$, et al. Eating habits and lifestyle changes during COVID-19 lockdown: an Italian survey. J Transl Med. 2020 Jun 8;18(1):229.

4. Giustino V, Parroco AM, Gennaro A, Musumeci G, Palma A, Battaglia G. Physical Activity Levels and Related Energy Expenditure during COVID-19 Quarantine among the Sicilian Active Population: A Cross-Sectional Online Survey Study. Sustainability 2020; 12: 4356.

5. WHO. Global Recommendations on Physical Activity for Health (Geneva, Switzerland) 2010.

6. WHO. Obesity: preventing and managing the global epidemic 2000.
7. Husain W, Ashkanani F. Does COVID-19 change dietary habits and lifestyle behaviours in Kuwait: a community-based cross-sectional study. Environ Health Prev Med 2020; 25:61.

8. Deschasaux-Tanguy M, Druesne-Pecollo N, Esseddik Y, de Edelenyi FS, Alles B, Andreeva VA, et al. Diet and Physical Activity during the COVID-19 Lockdown Period (March-May 2020): Results from the French NutriNet-Sante Cohort Study. [(accessed on 16 August 2020)];MedRxiv. 2020 Available online: https://www.medrxiv.org/content/10.1101/2 020.06.04.20121855v1.

9. Sidor A, Rzymski P. Dietary choices and habits during COVID-19 lockdown: Experience from Poland. Nutrients. 2020;12:1657.

10. Rodríguez-Pérez C, Molina-Montes E, Verardo V, Artacho R, García-Villanova B, Guerra-Hernández EJ, Ruíz-López MD. Changes in dietary behaviours during the COVID-19 outbreak confinement in the Spanish COVIDiet Study. Nutrients. 2020;12:1730.

11. Ammar A, Brach M, Trabelsi K, Chtourou $\mathrm{H}$, Boukhris O, Masmoudi L, et al. Effects of COVID-19 home confinement on eating behaviour and physical activity: Results of the ECLB-COVID19 International Online Survey. Nutrients. 2020;12:1583.

12. Górnicka, M, Drywień, ME, Zielinska, MA, Hamułka, J. 2020. "Dietary and Lifestyle Changes During COVID-19 and the Subsequent Lockdowns among Polish Adults: A Cross-Sectional Online Survey PLifeCOVID-19 Study" Nutrients 2020;12(8): 2324.

13. Pellegrini M, Ponzo V, Rosato R, Scumaci E, Goitre I, Benso A, et al. Changes in weight and nutritional habits in adults with obesity during the "lockdown" period caused by the COVID-19 virus emergency. Nutrients 2020; 12:2016.

14. Rolland B, Haesebaert F, Zante E, Benyamina A, Haesebaert J, Franck N. Global changes and factors of increase in caloric/salty food, screen, and substance use, during the early COVID-19 containment phase in France: A general population online survey. J. Med. Internet Res. 2020; 6: e19630.

15. AlMughamis N, Alasfour S, Mehmood S. Poor eating habits and predictors of weight 
gain during the COVID-19 quarantine measures in Kuwait: A cross sectional study. F1000Research 2020; 9:914. Available online: https://f1000research.com/articles/9-914/v1 (accessed on 18 August 2020).

16. Bann D, Villadsen A, Maddock J, Hughes A, Ploubidis G, Silverwood R, Patalay P. Changes in the Behavioural Determinants of Health during the Coronavirus (COVID-19) Pandemic: Gender, Socioeconomic and Ethnic Inequalities in 5 British Cohort Studies. MedRxiv 2020. Available online: https://www.medrxiv.org/content/10.1101/2 020.07.29.20164244v1 (accessed on 18 August 2020).

17. Kriaucioniene V, Bagdonaviciene L, Rodríguez-Pérez C, Petkeviciene J. Associations between Changes in Health Behaviours and Body Weight during the COVID-19 Quarantine in Lithuania: The Lithuanian COVIDiet Study. Nutrients. 2020; 12(10):3119.

18. López-Bueno R, Calatayud J, Casaña J, Casajús JA, Smith L, Tully MA, et al. COVID-19 Confinement and Health Risk Behaviors in Spain. Front. Psychol. 2020;11:1426.

19. Cancello R, Soranna D, Zambra G, Zambon A, Invitti C. Determinants of the Lifestyle Changes during COVID-19 Pandemic in the Residents of Northern Italy. International Journal of Environmental Research and Public Health. 2020; 17(17):6287.
20. Scarmozzino F, Visioli F. Covid-19 and the Subsequent Lockdown Modified Dietary Habits of Almost Half the Population in an Italian Sample. Foods. 2020; 9(5):675.

21. Đogaš Z, Lušić Kalcina L, Pavlinac Dodig I, Demirović S, Madirazza $K$, Valić $M$, Pecotić R. The effect of COVID-19 lockdown on lifestyle and mood in Croatian general population: a cross-sectional study. Croat Med J. 2020 Aug 31;61(4):309-318.

22. Jia P, Zhang L, Yu W, Yu B, Liu M, Zhang D, Yang S. Impact of COVID-19 lockdown on activity patterns and weight status among youths in China: the COVID-19 Impact on Lifestyle Change Survey (COINLICS). Int J Obes (Lond). 2020 Dec 4:1-5.

23. Giacalone D, Frøst MB, Rodríguez-Pérez C. Reported Changes in Dietary Habits During the COVID-19 Lockdown in the Danish Population: The Danish COVIDiet Study. Front Nutr. 2020 Dec 8;7:592112.

24. Hills AP, Byrne NM, Lindstrom R, Hill JO. 'Small changes' to diet and physical activity behaviors for weight management. Obes. Facts 2013, 6, 228-238.

How to cite this article: Galfo M, Maccati F, Melini F. Effects of COVID-19 pandemic on lifestyle behaviours among Italian physically active population. Int J Health Sci Res. 2021; 11(4): 12-20. DOI: https://doi.org/10.52403/ ijhsr.20210402 